\section{Successful endoscopic submucosal dissection of duodenal cancer}

This is the first report of complete resection of early duodenal cancer using endoscopic submucosal dissection (ESD) monotherapy.

A 66-year-old Japanese man visited the hospital in order to undergo screening for cancer on June 2004. Endoscopic examination of the upper digestive tract revealed a faintly marked, red, depressed (0-IIc) lesion, $3.5 \times 3.0 \mathrm{~mm}$ in diameter, on the posterior wall of the duodenal cap ( $\bullet$ Fig. 1). The biopsy specimen obtained from the lesion revealed a well-differenti- ated tubular adenocarcinoma ( $\bullet$ Fig. 2). No metastasis to any other organ was found. A barium X-ray study showed there was no notable duodenal transformation. In addition, the lesion showed the lifting sign after submucosal saline injection $[1,2]$. This lesion was diagnosed as a mucosal duodenal cancer. ESD was selected for this patient after histological confirmation of the diagnosis. A cylindrical transparent hood was attached to the endoscope to maintain a satisfactory view during the procedure.
ESD was carried out primarily using the flex knife (KD-630L; Olympus) and hook knife (KD-620LR; Olympus) as described previously by Kodashima and Rösch $[3,4]$ ( Fig. 3). Bleeding during the procedure was managed by the administration of thrombin and by snare coagulation. Some hemoclips were also used to prevent perforation ( Fig. 4). No recurrence has been found in more than 3 years since ESD ( $\bullet$ Fig. 5 ). In this patient, the successful outcome depended on two points: (i) the use of hemoclips on the scar after resection, and (ii) the attachment of a cylindrical transparent hood to the endoscope, which together made the ESD easier and safer.

ESD might be one of the most effective and useful techniques for the treatment of early duodenal cancer in the future.

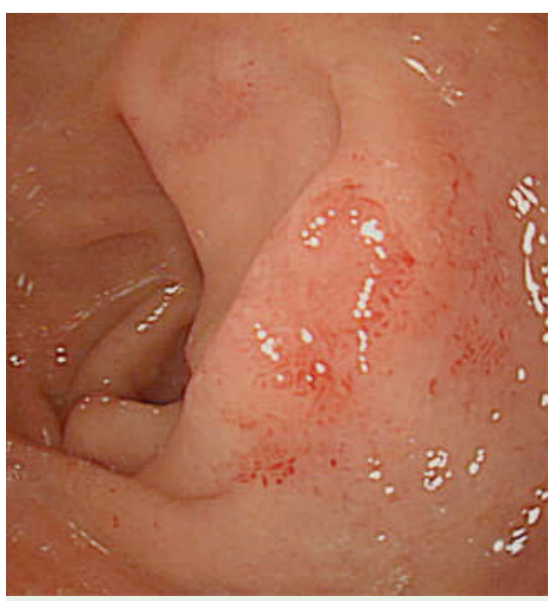

Fig. 1 An endoscopic examination of the upper digestive tract revealed a faintly marked, red, depressed (0-IIc) lesion, $3.5 \times 3.0 \mathrm{~mm}$ in diameter, on the posterior wall of the duodenal cap.

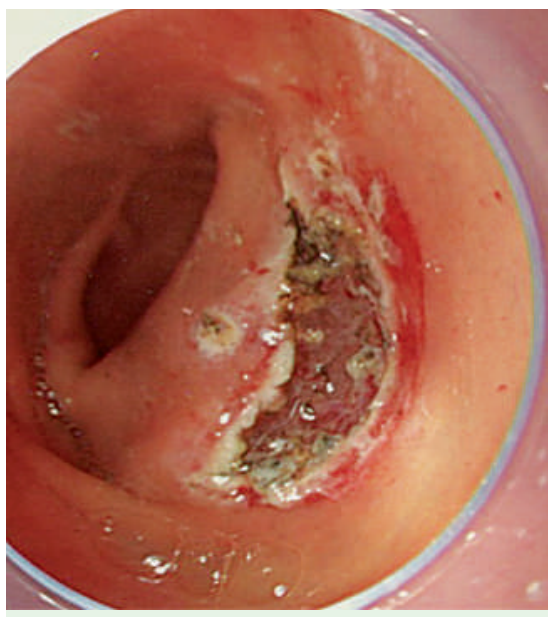

Fig. 3 The lesion was completely resected with a safe lateral and vertical margin.

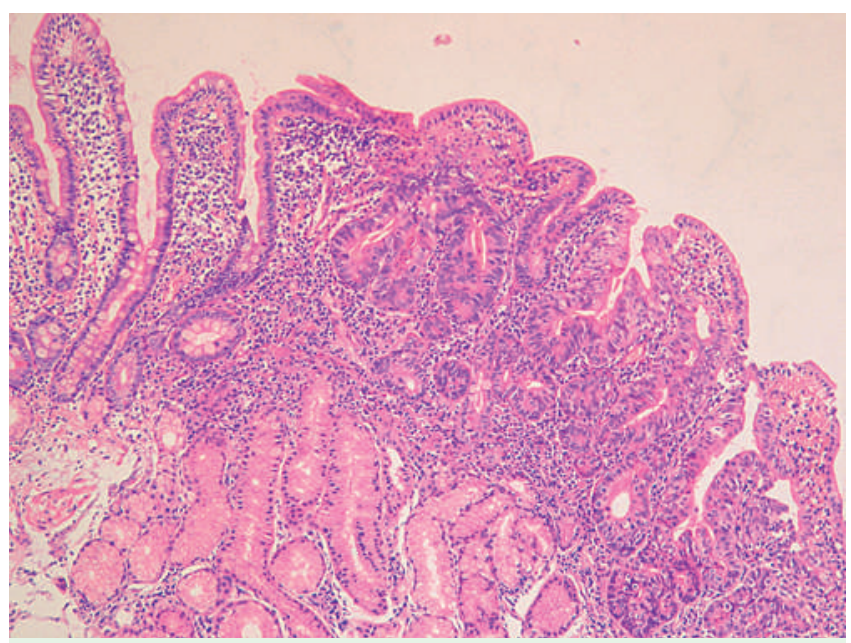

Fig. 2 The biopsy specimen obtained from the lesion revealed a welldifferentiated tubular adenocarcinoma $(\mathrm{H} \& \mathrm{E}$, original magnification $\times 40$ ).

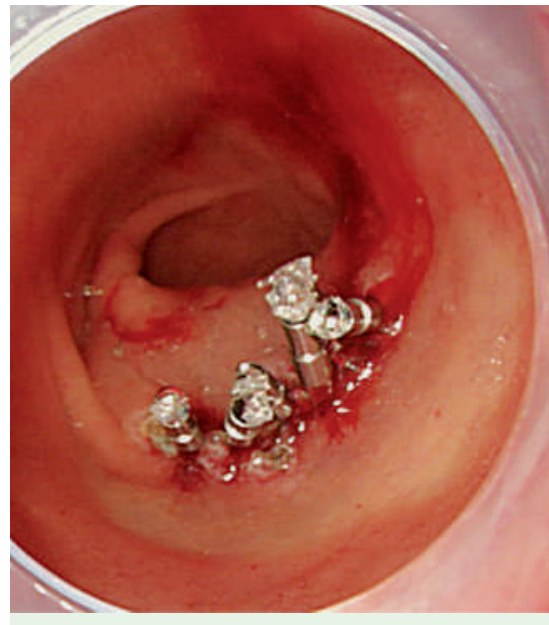

Fig. 4 After the resection the scar was closed by hemoclips to prevent perforation.

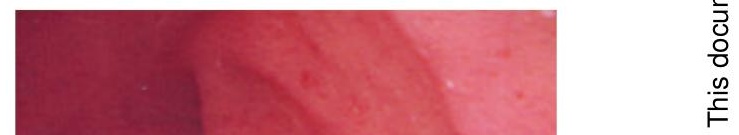

Fig. 5 No recurrence has been observed in more than 3 years since the ESD was carried out. 
Endoscopy_UCTN_Code_TTT_1AO_2AG

S. Yoshida ${ }^{1}$, M. Shimada ${ }^{1}$, T. Ueno ${ }^{2}$, Y. Kitamura ${ }^{1}$, S. Matsuzaki ${ }^{1}$,

S. Nishikubo ${ }^{1}$, M. Nagae ${ }^{1}$, K. Nakanishi ${ }^{3}$, J. Murata ${ }^{4}$, M. Yoshino ${ }^{1}$

Department of Gastroenterology, Internal Medicine, TMG Asakadai Central General Hospital, Saitama, Japan

2 Critical Care Medicine, Hachioji Medical Center, Tokyo Medical University, Tokyo, Japan

3 Department of Pathology, National Defense Medical College, Saitama, Japan

4 Department of Digestive Surgery, TMG Asakadai Central General Hospital, Saitama, Japan

\section{References}

1 Han KS, Sohn DK, Choi DH et al. Prolongation of the period between biopsy and EMR can influence the nonlifting sign in endoscopically resectable colorectal cancers. Gastrointest Endosc 2008; 67: 97 - 102

2 Kobayashi N, Saito Y, Sano Yet al. Determining the treatment strategy for colorectal neoplastic lesions: endoscopic assessment or the non-lifting sign for diagnosing invasion depth? Endoscopy 2007; 39: $701-705$

3 Kodashima S, Fujishiro M, Yahagi N et al. Endoscopic submucosal dissection using flexknife. J Clin Gastroenterol 2006; 40: 378 384

4 Rösch T, Sarbia M, Schumacher B et al. Attempted endoscopic en bloc resection of mucosal and submucosal tumors using insulated-tip knives: a pilot series. Endoscopy 2004; 36: $788-801$
Bibliography

DOI $10.1055 / \mathrm{s}-2007-995685$

Endoscopy 2008; 40: E132 -E133

(c) Georg Thieme Verlag KG Stuttgart · New York . ISSN 0013-726X

\section{Corresponding author}

\section{Shimada, MD, PhD}

Department of Gastroenterology Internal Medicine

TMG Asakadai Central General Hospital

1-8-10, Nishi-benzai, Asaka-shi

Saitama 351-8551

Japan

Fax: + 81-48-4662735

shimada@kanazawa-med.ac.jp 